\title{
INFLUÊNCIA DO MODELO DE ANÁLISE ESTATÍSTICA E DA FORMA DAS PARCELAS EXPERIMENTAIS NA SELEÇÃO DE CLONES DE Eucalyptus spp. ${ }^{1}$
}

\author{
Edimar Aparecido Scarpinati ${ }^{2}$, Dilermando Perecin ${ }^{3}$, Rinaldo César de Paula ${ }^{4}$, César Augusto Valencise
} Bonine $^{2}$, Bruno Ettore Pavan ${ }^{5}$ Liliam Silva Candido ${ }^{5}$

\begin{abstract}
RESUMO - Foram avaliadas três formas de parcelas experimentais (retangular, uma linha - linear e parcela de uma árvore - STP) em testes clonais de Eucalyptus spp, utilizando-se três experimentos, cada um com 18 clones. Foram usados três modelos de análise (mínimos quadrados ordinários - ANOVA tradicional, modelos mistos com fator clone fixo ou com fator clone aleatório - REML/BLUP). Os dois primeiros modelos apresentaram resultados similares. Com REML/BLUP houve estreitamento das predições em relação às amplitudes obtidas com as médias, e essa redução foi proporcionalmente maior com parcelas retangulares e STP. O ordenamento dos clones também foi similar com esses dois tipos de parcelas. É provável que com parcelas STP haja um balanço compensatório das alocompetições, pois se pode trabalhar com maior número de repetições e menor custo. Portanto, com parcelas STP haverá economia de recursos e sem prejuízos para o Programa de Melhoramento Florestal.
\end{abstract}

Palavras-chave: Eucalipto, delineamento experimental e modelos mistos.

\section{INFLUENCES OF EXPERIMENTAL PLOT FORMS AND STATISTICAL MODEL ANALYSIS IN Eucalyptus spp CLONE SELECTIONS}

\begin{abstract}
Three experimental plot forms (rectangular, one line - linear and single tree plot-STP) were evaluated for Eucalyptus spp clonal tests, using three experiments with 18 clones each. Three analysis models (ordinary least square - traditional ANOVA, mixed models with fixed clone factor or with random clone factorREML/BLUP) were used. The first and second models showed similar results. With REML/BLUP, there was a reduction in the range of prediction compared to the amplitudes obtained employing the means. This reduction was proportionally higher with rectangular and STP plots. The ranking of clones was also similar to these two types of plots. Probably, there was a compensatory balance of alocompetition with STP plots, because it is possible to work with a higher number of repetitions and lower costs. Therefore, the use of STP plots results in resource saving, preventing losses in forest breeding programs.
\end{abstract}

Keywords: Eucalyptus, experimental design and mixed models.

\section{INTRODUÇÃO}

A etapa final de um Programa de Melhoramento Genético Florestal é o teste clonal dos genótipos selecionados em testes de progênies ou em seleção massal de plantios seminais. O teste clonal é, portanto, a base para definição de quais genótipos poderão ser explorados comercialmente.
Uma grande dificuldade nesse processo é a clonagem dos genótipos selecionados. Geralmente, no gênero Eucalyptus a clonagem é realizada através de partes dos ramos vegetais. De acordo com Higashi et al. (2000), o sucesso da técnica está associado com as características intrínsecas ao genótipo selecionado como fatores químicos (endógenos ou exógenos) e fatores fisiológicos em detrimento dos

\footnotetext{
${ }^{1}$ Recebido em 28.09.2007 e aceito para publicação em 29.05.2009.

${ }^{2}$ Fibria. E-mail: <edimar.scarpinati@ fibria.com.br>.

${ }^{3}$ Departamento de Ciências Exatas da Universidade Estadual Paulista (UNESP). Bolsista PQ-CNPq. E-mail: <perecin@ fcav.unesp.br>.

${ }^{4}$ Departamento de Produção Vegetal da UNESP e Bolsista PQ-CNPq. E.mail:<rcpaula@ fcav.unesp.br>.

${ }^{5}$ DoutoresemAgronomia(Genéticae MelhoramentodePlantas) pelaUNESP.E-mail: <brunoe.pavan@ig.com.br>e<bioliliam@yahoo.com.br>.
} 
efeitos ambientais. Essa dificuldade atrelada aos custos de implantação dos experimentos torna essa etapa dificultosa para o melhorista florestal testar em campo todos os genótipos selecionados (ZOBEL, 1993). Muitas vezes, não se conseguem mudas suficientes em determinado período de tempo, que atenda às necessidades dos delineamentos experimentais.

Nesse sentido, procuram-se utilizar delineamentos experimentais que sejam adequados à sua situação em relação ao tamanho, forma e número de repetições das parcelas experimentais, a fim de diminuir os erros oriundos da heterogeneidade das parcelas e, com isso, maximizar os ganhos de seleção (ZANON e STORCK, 1997).

A consequência direta da heterogeneidade das parcelas e das variâncias em diferentes níveis de predição é o risco de selecionar indivíduos de maior variabilidade fenotípica e não de maior valor genético, podendo, com isto, ocorrer redução do progresso genético esperado (RAMOS et al., 1996). Andrade et al. (2006) consideraram que as perdas de plantas por incidência de pragas ou doenças são também um fator de heterogeneidade das parcelas.

Em testes clonais com eucalipto, Silva et al. (2003) concluíram que parcelas com 5 a 10 plantas são as mais adequadas para seleção precoce, e, para inferências visando ao uso em plantios comerciais, parcelas maiores ou plantios-piloto são mais indicados. Já, de acordo com Gomes e Couto (1985), é possível diminuir o tamanho das parcelas sem prejuízos para a seleção e com economia ao setor florestal. De acordo com Resende (1995), fixandose um número total de indivíduos por família, parcelas com um indivíduo e muitas repetições sempre conduzem a maior acurácia em relação às parcelas com vários indivíduos e poucas repetições.

Além do delineamento experimental, outro fator que preocupa os pesquisadores é a escolha da metodologia de análise que minimize a interferência das variáveis nos resultados de seleção. Como a seleção de genótipos em testes clonais com eucalipto leva em torno de cinco a sete anos, aumenta-se a chance das interferências ambientais na seleção dos genótipos.

Segundo Resende (2000), além da variabilidade do material genético experimental, o sucesso do melhoramento genético depende quase que totalmente da adoção de métodos precisos de seleção. De acordo com esse autor, a estimação baseada no método dos quadrados mínimos como a aplicada na análise de variância não é a mais recomendada para plantas perenes, principalmente porque, em muitos casos, ocorre desbalanceamento excessivo no experimento. Com isso, os dados não apresentam homogeneidade de variância, e, portanto, os modelos mistos seriam os mais adequados para análise dos dados.

De acordo com Resende (1996), a estimação e predição no contexto de plantas perenes demandam o uso da metodologia de modelos mistos em nível individual, conforme metodologia adaptada de Henderson (1975). Segundo esse autor, o método da predição de valores genéticos, denominado predição linear não viesada (REML/BLUP), é fundamental no conhecimento ou estimação precisa dos componentes de variâncias genética e fenotípica.

O objetivo deste trabalho foi avaliar as alterações no ordenamento de genótipos na seleção de clones de eucalipto em função do modelo estatístico empregado na análise experimental e do tipo de parcelas experimentais.

\section{MATERIAL E MÉTODOS}

Os testes clonais foram instalados na fazenda Cara Preta, propriedade da Votorantim Celulose e Papel S.A. (VCP), no Município de Santa Rita do Passa Quatro, SP, em maio de 2003. O local do experimento encontrase a $21^{\circ} 37$ de latitude sul e a $47^{\circ} 37^{\prime}$ de longitude oeste, com precipitação média anual de $1.300 \mathrm{~mm}$ e temperaturas médias de inverno e verão de $15{ }^{\circ} \mathrm{C}$ e $31{ }^{\circ} \mathrm{C}$, respectivamente. A classificação do solo da área experimental é Neossolo Quartzarênico.

Foram instalados três testes clonais de Eucalyptus spp, a partir de materiais genéticos com alto desempenho silvicultural para a característica Incremento Médio Anual de Volume (IMA). A opção por genótipos de alta produtividade objetivou minimizar as influências de clones superiores sobre materiais genéticos inferiores ou com comportamento desconhecidos nos resultados. A adubação e tratos culturais seguiram as recomendações de plantio operacional utilizada na empresa. Cada experimento foi separado por bordadura simples de uma linha, com material genético comercialmente plantado pela empresa.

As características de cada experimento estão descritas a seguir: 
Experimento 1: Teste clonal em delineamento de blocos ao acaso com seis repetições e parcelas retangulares com 42 plantas (6 linhas x 7 plantas). O espaçamento de plantio foi de 3,0 m entre linhas e 2,5 m entre plantas, sendo consideradas as seis plantas centrais como parcela útil, totalizando uma área experimental de 3,4 ha.

Experimento 2: Teste clonal em delineamento de blocos as acaso, com seis repetições e parcelas lineares de 10 plantas, considerando-se todas as plantas da parcela como parcela útil. O espaçamento de plantio foi de 3,0 m entre linhas e 2,5 m entre plantas, com uma área total experimental de 0,81 ha.

Experimento 3: Teste clonal em delineamento de blocos ao acaso, com 20 repetições e uma planta por parcela (single tree plot - STP). O espaçamento de plantio também foi de 3,0 $\mathrm{m}$ entre linhas e 2,5 m entre plantas, totalizando uma área experimental de 0,27 ha.

No campo, os três experimentos com as respectivas parcelas situaram-se em áreas aparentemente uniformes e anexas (uma ao lado da outra).

Aos 3 anos de idade foram avaliadas as características: altura $(\mathrm{m})$, determinada com clinômetro eletrônico, e diâmetro à altura do peito (DAP, em m), determinado com fita métrica. Com os dados de altura e DAP, efetuou-se o cálculo do volume de madeira, utilizando-se fator de forma por classe diamétrica, determinado e fornecido pelo Departamento de Inventário Florestal da empresa.

Após o cálculo do volume das árvores, o resultado foi multiplicado pelo estande/ha $\left(\mathrm{n}^{\circ}\right.$ de plantas/ha no espaçamento de plantio 3,0 $\mathrm{m}$ x 2,5 m) utilizado em plantios comerciais com eucalipto na região de Ribeirão Preto, SP. Para cálculo do IMA, dividiu-se o resultado obtido por 3, que foi a idade de avaliação utilizada neste trabalho.

Os dados do IMA foram avaliados por três metodologias de análise: a) tradicional (ANOVA), obtida através do método dos mínimos quadrados ordinários, considerando clone como fixo e bloco aleatório; b) modelo misto com clone fixo; e c) modelo misto com clone aleatório (REML/BLUP). As estimativas de interesse foram obtidas utilizando-se os procedimentos GLM e MIXED do software estatístico SAS (1999).

Para a estimativa da herdabilidade no sentido amplo e em nível de clone, utilizaram-se somente os dados das estimativas obtidas no modelo misto com clone aleatório (REML/BLUP), sendo obtida conforme Vencovsky e Barriga (1992).
Para comparação entre os experimentos, constituídos por parcelas de diferentes formas, foi efetuada uma análise conjunta, utilizando-se modelo misto com clone aleatório (REML/BLUP).

O ordenamento dos clones foi feito em função do delineamento e do modelo estatístico.

\section{RESULTADOS E DISCUSSÃO}

Os resultados de comparação dos experimentos dentro dos três modelos de análise para cada experimento estão sumarizados nas Tabelas 1, 2 e 3.

\section{Delineamento de blocos ao acaso em parcelas retangulares}

Os resultados estão resumidos na Tabela 1 . O valor de F para efeito de clone foi igual nos modelos tradicional e misto com clone fixo $(3,34)$, ou seja, as duas análises apresentaram a mesma eficiência para diferenciação dos clones.

Os coeficientes de variação (CV\%) obtidos dos três modelos de análises praticamente não se alteraram, conforme a Tabela 1. O mesmo comportamento (em menor escala) foi observado no coeficiente de variação dentro das parcelas. Esses coeficientes de variação podem ser classificados como médios, conforme proposição de Garcia (1987). Como o caráter IMA é uma composição do volume, obtido pelas variáveis altura e DAP, é comum apresentar maior coeficiente de variação, conforme comentado por Houle (1992).

As estimativas das variâncias de clones $\left(\hat{\sigma}_{\mathrm{g}}^{2}\right)$ do erro entre parcelas $\left(\hat{\sigma}_{\mathrm{e}}^{2}\right)$ foram 7,78 e 0 , respectivamente. A interação clone $\mathrm{x}$ bloco foi praticamente nula e isso indica que os efeitos de clones foram igualmente manifestados em todos os blocos, possivelmente por se tratar de árvores mensuradas somente em autocompetição em função do próprio delineamento experimental.

As estimativas da variância dentro de parcelas $\left(\hat{\sigma}_{d}^{2}\right)$ praticamente não se alteraram $(116,48$ na análise tradicional; 116,55 no modelo misto com clone fixo; e 116,64 no modelo misto com clone aleatório). Da mesma forma, valor próximo desses foi observado no quadrado médio do erro entre parcelas (QME) da análise tradicional.

R. Árvore, Viçosa-MG, v.33, n.4, p.769-776, 2009 
Tabela 1 - Resultados obtidos da análise do teste clonal com parcelas retangulares quanto ao caráter Incremento Volumétrico Médio Anual (IMA), segundo três modelos de análise

Table 1 -Results obtained from the clonal test analysis with rectangular plots to the Annual Average Volumetric Increment characteristic (IMA)

\begin{tabular}{|c|c|c|c|}
\hline Parâmetros & $\begin{array}{c}\text { ANOVA } \\
\text { Tradicional }\end{array}$ & $\begin{array}{c}\text { Misto } \\
\text { clone fixo }\end{array}$ & $\begin{array}{c}\text { Misto clone } \\
\text { aleatório }\end{array}$ \\
\hline$\overline{\text { F Clone* }}$ & 3,34 & 3,34 & - \\
\hline$\sigma_{\mathrm{g}}^{2}$ clone & - & - & 7,78 \\
\hline$\sigma^{\frac{g}{2}}$ (entre parcelas) & 0,15 & 0 & 0 \\
\hline QME & 117,36 & - & - \\
\hline$\sigma_{\mathrm{d}}^{2}$ & 116,48 & 116,55 & 116,64 \\
\hline $\mathrm{h}^{2}$ (amplo) & - & - & 0,71 \\
\hline $\begin{array}{l}\text { Média geral } \\
\left(\mathrm{m}^{3} / \mathrm{ha} / \mathrm{ano}\right)\end{array}$ & 40,02 & 40,02 & 40,02 \\
\hline CV\%(exp) & 26,97 & 27,24 & 26,14 \\
\hline CV\%(parcela) & 26,27 & 27,24 & 26,14 \\
\hline $\begin{array}{l}\text { Amplitude entre } \\
\text { clones }\end{array}$ & 13,54 & 13,54 & 9,32 \\
\hline Ordenação/ clones & $\begin{array}{l}\text { Clone } \\
\text { (IMA) }\end{array}$ & $\begin{array}{l}\text { Clone } \\
\text { (IMA) }\end{array}$ & $\begin{array}{l}\text { Clone } \\
\text { (IMA) }\end{array}$ \\
\hline $1^{\circ}$ & $14(49,13)$ & $14(49,13)$ & $14(48,19)$ \\
\hline $2^{\circ}$ & $05(44,87)$ & $05(44,87)$ & $05(45,43)$ \\
\hline $3^{\circ}$ & $08(43,18)$ & $08(43,18)$ & $08(44,23)$ \\
\hline $4^{\circ}$ & $13(42,64)$ & $13(42,64)$ & $13(43,81)$ \\
\hline $5^{\circ}$ & $01(41,90)$ & $01(41,90)$ & $11(42,44)$ \\
\hline $6^{\circ}$ & $11(40,64)$ & $11(40,64)$ & $04(42,37)$ \\
\hline $7^{\circ}$ & $04(40,54)$ & $04(40,54)$ & $18(41,93)$ \\
\hline $8^{\circ}$ & $18(40,02)$ & $18(40,02)$ & $16(41,84)$ \\
\hline $9^{\circ}$ & $16(39,79)$ & $16(39,79)$ & $12(41,54)$ \\
\hline $10^{\circ}$ & $12(39,37)$ & $12(39,37)$ & $02(41,19)$ \\
\hline $11^{\circ}$ & $02(38,81)$ & $02(38,81)$ & $10(40,68)$ \\
\hline $12^{\circ}$ & $10(38,15)$ & $10(38,15)$ & $01(40,67)$ \\
\hline $13^{\circ}$ & $15(38,00)$ & $15(38,00)$ & $06(40,60)$ \\
\hline $14^{\circ}$ & $06(37,99)$ & $06(37,99)$ & $09(40,57)$ \\
\hline $15^{\circ}$ & $09(37,99)$ & $09(37,99)$ & $15(40,56)$ \\
\hline $16^{\circ}$ & $17(36,42)$ & $17(36,42)$ & $17(39,54)$ \\
\hline $17^{\circ}$ & $03(36,02)$ & $03(36,02)$ & $03(39,24)$ \\
\hline $18^{\circ}$ & $07(35,59)$ & $07(35,59)$ & $07(38,87)$ \\
\hline
\end{tabular}

*significativo a $1 \%$ de probabilidade, $\sigma_{\mathrm{g}}^{2}$ clone=variância de clone, $\sigma^{2}=$ variância entre parcelas, QME=quadrado médio entre parcelas, $\sigma_{d}^{2}=$ variância do erro dentro de parcelas, $\mathrm{CV} \%(\exp )=$ coeficiente de variação experimental, $\mathrm{CV} \%$ (parcela)=coeficiente de variação dentro das parcelas.

A estimativa da herdabilidade no sentido amplo foi de 0,71 , indicando alta possibilidade de ganhos com seleção de clones.

A amplitude do incremento volumétrico médio anual (IMA), entre os clones de melhor e pior desempenho, reduziu de $13,54 \mathrm{~m}^{3} / \mathrm{ha} /$ ano para $9,32 \mathrm{~m}^{3} / \mathrm{ha} /$ ano no modelo misto com clone aleatório (redução de $31,1 \%$ ). Essa redução é denominada "Shrinkage", causada pelo fato de os valores estarem mais livres dos efeitos ambientais, sendo abordada teoricamente por Duarte e Vencosvsky (2001).

Para o ordenamento dos clones, não houve diferença entre as análises tradicional e modelo misto com clones fixos. Já no modelo REML/BLUP houve mudança de posição entre os clones intermediários $\left(5^{\circ}\right.$ ao $\left.15^{\circ}\right)$, havendo, na maioria dos clones, mudança de apenas uma posição. O clone 1 , contudo, passa do $5^{\circ}$ colocado no modelo tradicional e misto com clone fixo para o $12^{\circ}$ no modelo REML/BLUP, porém com as estimativas de médias muito próximas entre os métodos de análise.

\section{Delineamento de blocos ao acaso em parcelas lineares}

Os resultados estão resumidos na Tabela 2. $\mathrm{Na}$ análise tradicional e no modelo misto com clone fixo, os valores de $\mathrm{F}$ em clones foram iguais, apresentando mesma eficiência para diferenciação dos clones.

Os coeficientes de variação do experimento e dentro da parcela também foram iguais, $29,93 \%$ dentro das parcelas e $36,91 \%$ no experimento, nos três modelos. Esses coeficientes de variação podem ser considerados médios, conforme a proposição de Garcia (1987).

As estimativas das variâncias de clones e do erro entre parcelas foram 14,56 e 7,59, respectivamente. Em relação à parcela retangular (Tabela 1), as variâncias aqui obtidas são um pouco maiores, possivelmente devido à competição entre materiais distintos (alocompetição).

Em relação às estimativas da variância dentro das parcelas $\left(\hat{\sigma}_{d}^{2}\right)$, elas praticamente se mantiveram iguais nos três modelos.

A estimativa da herdabilidade no sentido amplo foi 0,80 , valor adequado com literaturas de testes com clones (VENCOVSKY e BARRIGA, 1992), demonstrando possibilidade de ganhos com seleção de clones.

No modelo misto, a amplitude do incremento volumétrico médio anual (IMA) é reduzida de 16,64 $\mathrm{m}^{3} / \mathrm{ha} / \mathrm{ano}$, nos modelos tradicional e misto com clone fixo, para $14,38 \mathrm{~m}^{3} / \mathrm{ha} /$ ano no modelo misto com clone aleatório, ou seja, redução de $13,6 \%$, portanto menor que no experimento em parcelas retangulares, porém novamente aparece o efeito "shrinkage".

Para o ordenamento dos clones, os três métodos de análise apresentaram a mesma classificação dos genótipos, não havendo, portanto, diferença na seleção dos clones em função do modelo utilizado, o que possivelmente se deve ao quase perfeito balanceamento do delineamento. 


\section{Delineamento de blocos ao acaso em parcelas de planta única (STP)}

Assim como nas parcelas em linha e retangular, os valores de F nos clones do experimento em STP foram iguais $(6,99)$ nos modelos tradicional e misto com clone fixo, apresentando mesma eficiência na diferenciação de clones.

Tabela 2 - Resultados obtidos na análise do teste clonal com parcelas lineares quanto ao caráter Incremento Volumétrico Anual (IMA), seguindo três modelos de análise

Table 2 - Results obtained from the clonal test analysis with linear plots to the Annual Average Increment Characteristic (IMA)

\begin{tabular}{|c|c|c|c|}
\hline Parâmetros & $\begin{array}{c}\text { ANOVA } \\
\text { Tradicional }\end{array}$ & $\begin{array}{c}\text { Misto } \\
\text { clone fixo }\end{array}$ & $\begin{array}{c}\text { Misto clone } \\
\text { aleatório }\end{array}$ \\
\hline F Clone* & 7,52 & 7,52 & - \\
\hline$\sigma_{\alpha}^{2}$ clone & - & - & 14,56 \\
\hline$\sigma_{\mathrm{e}}^{2}$ (entre parcelas) & 7,56 & 7,53 & 7,59 \\
\hline QME & 214,84 & - & - \\
\hline$\sigma_{d}^{2}$ & 141,27 & 141,29 & 141,26 \\
\hline $\mathrm{h}^{\mathrm{d}}$ (amplo) & - & - & 0,80 \\
\hline $\begin{array}{l}\text { Média geral } \\
\left(\mathrm{m}^{3} / \mathrm{ha} / \mathrm{ano}\right)\end{array}$ & 39,71 & 39,71 & 39,71 \\
\hline CV\%(exp) & 36,91 & 36,91 & 36,91 \\
\hline CV\%(parcela) & 29,93 & 29,93 & 29,93 \\
\hline $\begin{array}{l}\text { Amplitude } \\
\text { entre clones }\end{array}$ & 16,64 & 16,64 & 14,38 \\
\hline Ordenação/clones & $\begin{array}{l}\text { Clone } \\
\text { (IMA) }\end{array}$ & $\begin{array}{l}\text { Clone } \\
\text { (IMA) }\end{array}$ & $\begin{array}{l}\text { Clone } \\
\text { (IMA) }\end{array}$ \\
\hline $1^{\circ}$ & $08(48,12)$ & $08(48,07)$ & $08(46,94)$ \\
\hline $2^{\circ}$ & $05(44,72)$ & $05(44,68)$ & $05(44,03)$ \\
\hline $3^{\circ}$ & $04(44,47)$ & $04(44,43)$ & $04(43,77)$ \\
\hline $4^{\circ}$ & $13(42,91)$ & $13(42,93)$ & $13(42,50)$ \\
\hline $5^{\circ}$ & $10(42,85)$ & $10(42,83)$ & $10(42,36)$ \\
\hline $6^{\circ}$ & $14(42,65)$ & $14(42,61)$ & $14(42,23)$ \\
\hline $7^{\circ}$ & $06(42,43)$ & $06(42,49)$ & $06(42,09)$ \\
\hline $8^{\circ}$ & $16(40,52)$ & $16(40,55)$ & $16(40,47)$ \\
\hline $9^{\circ}$ & $11(40,05)$ & $11(40,04)$ & $11(40,01)$ \\
\hline $10^{\circ}$ & $17(39,27)$ & $17(39,27)$ & $17(39,30)$ \\
\hline $11^{\circ}$ & $12(38,05)$ & $12(38,08)$ & $12(38,29)$ \\
\hline $12^{\circ}$ & $15(37,99)$ & $15(37,99)$ & $15(38,23)$ \\
\hline $13^{\circ}$ & $03(37,45)$ & $03(37,57)$ & $03(37,79)$ \\
\hline $14^{\circ}$ & $18(36,50)$ & $18(36,52)$ & $18(37,03)$ \\
\hline $15^{\circ}$ & $07(35,98)$ & $07(35,95)$ & $07(36,47)$ \\
\hline $16^{\circ}$ & $01(35,75)$ & $01(35,75)$ & $01(36,27)$ \\
\hline $17^{\circ}$ & $09(33,67)$ & $09(33,61)$ & $09(34,45)$ \\
\hline $18^{\circ}$ & $02(31,48)$ & $02(31,44)$ & $02(32,56)$ \\
\hline
\end{tabular}

*significativo a $1 \%$ de probabilidade, $\sigma^{2}$ clone=variância de clone, $\sigma^{2}=$ variância entre parcelas, $\mathrm{QME}=$ quadrado médio entre parcelas, $\sigma_{\mathrm{d}}^{2}=$ variância do erro dentro de parcelas, $\mathrm{CV} \%(\exp )=$ coeficiente de variação experimental, CV\% (parcela) $=$ coeficiente de variação dentro das parcelas.
Tabela 3 - Resultados obtidos na análise do teste clonal com parcelas de uma planta (STP) quanto ao caráter Incremento Médio Anual (IMA), seguindo três modelos de análise

Table 3 -Results obtained from the clonal test analysis with 1 plant (STP) plots to the Annual Average Increment characteristic (IMA)

\begin{tabular}{lccc}
\hline Parâmetros & $\begin{array}{c}\text { ANOVA } \\
\text { Tradicional }\end{array}$ & $\begin{array}{c}\text { Misto } \\
\text { clone fixo }\end{array}$ & $\begin{array}{c}\text { Misto clone } \\
\text { aleatório }\end{array}$ \\
\hline F Clone* & 6,99 & 6,99 & - \\
$\sigma_{\mathrm{g}}^{2}$ clone & - & - & 43,9 \\
$\sigma_{\mathrm{e}}^{2}$ & 145,12 & 144,31 & 145,12 \\
$\mathrm{~h}^{2}$ (amplo) & - & - & 0,84 \\
Média geral & 43,76 & 43,76 & 43,76 \\
$\left(\mathrm{~m}^{3} /\right.$ ha/ano) & & & \\
$\mathrm{CV} \%($ exp) & 27,53 & 27,53 & 27,53 \\
Amplitude & 23,28 & 23,21 & 19,98 \\
entre clones & & & \\
\hline Ordenação/ clones & Clone & Clone & Clone \\
& (IMA) & $(\mathrm{IMA})$ & $(\mathrm{IMA})$ \\
\hline $1^{\circ}$ & $14(56,44)$ & $14(56,44)$ & $14(54,67)$ \\
$2^{\circ}$ & $04(53,47)$ & $04(53,47)$ & $04(52,12)$ \\
$3^{\circ}$ & $13(52,98)$ & $13(52,98)$ & $13(51,70)$ \\
$4^{\circ}$ & $08(49,20)$ & $08(49,20)$ & $08(48,45)$ \\
$5^{\circ}$ & $05(49,06)$ & $05(49,06)$ & $05(48,34)$ \\
$6^{\circ}$ & $06(47,68)$ & $06(47,68)$ & $06(47,15)$ \\
$7^{\circ}$ & $11(46,84)$ & $11(46,84)$ & $11(46,43)$ \\
$8^{\circ}$ & $10(46,57)$ & $10(46,57)$ & $10(46,20)$ \\
$9^{\circ}$ & $16(44,65)$ & $16(44,65)$ & $16(44,45)$ \\
$10^{\circ}$ & $12(44,01)$ & $12(44,01)$ & $12(44,06)$ \\
$11^{\circ}$ & $15(41,45)$ & $15(41,45)$ & $15(41,80)$ \\
$12^{\circ}$ & $09(41,36)$ & $09(41,36)$ & $09(41,73)$ \\
$13^{\circ}$ & $01(37,81)$ & $01(37,81)$ & $07(38,46)$ \\
$14^{\circ}$ & $07(37,55)$ & $07(37,55)$ & $01(37,97)$ \\
$15^{\circ}$ & $03(36,60)$ & $03(36,60)$ & $03(37,78)$ \\
$16^{\circ}$ & $17(34,73)$ & $17(36,16)$ & $02(36,04)$ \\
$17^{\circ}$ & $18(33,24)$ & $18(34,73)$ & $17(34,83)$ \\
$18^{\circ}$ & $02(33,16)$ & $02(33,24)$ & $18(34,69)$ \\
\hline
\end{tabular}

*significativo a $1 \%$ de probabilidade, $\sigma^{2}$ clone=variância de clone, $\sigma_{d}^{2}=$ variância entre parcelas, $\mathrm{CV} \%$ (parcella)=coeficiente de variação dentro das parcelas.

A estimativa da variância de erro entre parcelas (variância ambiental) praticamente não foi alterada entre os três métodos de análise. Também, não houve diferença do coeficiente de variação $(\mathrm{CV} \%)$ nos três modelos de análise.

A estimativa da variância entre clones foi de 43,90, e nesse tipo de delineamento não se inclui a variância da interação clone versus bloco, pois a planta é a própria parcela. Esse valor foi maior que nos dois casos anteriores, provavelmente pela maior influência da alocompetição, pois nessas condições a competição intergenotípica tende a aumentar, e cada genótipo responde diferentemente à competição, podendo elevar a variância entre clones.

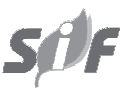

R. Árvore, Viçosa-MG, v.33, n.4, p.769-776, 2009 
A estimativa de herdabilidade no sentido amplo foi de 0,84 , maior que a dos dois casos anteriores. $O$ aumento da herdabilidade nesse caso possivelmente ocorreu em razão de o delineamento em parcela única apresentar menor efeito ambiental, sendo neste o número de árvore dentro de parcelas apenas 1, diminuindo, assim, os efeitos ambientais dentro das parcelas em relação aos demais.

Os valores das amplitudes do incremento volumétrico médio anual (IMA) foram de 23,28 $\mathrm{m}^{3} / \mathrm{ha} /$ ano na análise tradicional e $23,21 \mathrm{~m}^{3} / \mathrm{ha} /$ ano no modelo misto com clone fixo, enquanto no modelo misto com clone aleatório (REML/BLUP), de 19,98 m³/ha/ano. A redução de $13,9 \%$, nesse último caso, foi similar à obtida com o uso de parcelas lineares e menor que a conseguida com parcelas retangulares.

No ordenamento dos clones, não houve diferença entre as análises tradicional e do modelo misto com clones fixos. Em relação ao REML/BLUP, ocorreu alteração de posição entre os clones a partir do $13^{\circ}$ colocado.

\section{Comparação entre os delineamentos experimentais}

Para comparação entre os delineamentos pela análise do modelo misto e levando em conta clone aleatório (REML/BLUP), foram considerados três grupos de clones quanto ao desempenho, conforme Tabela 4.

Tabela 4 -Comparação do ordenamento entre os delineamentos experimentais pela análise de modelos mistos usando o REML/BLUP

Table 4-Ranking comparison between experimental designs and mixed model analysis using REML/BLUP

\begin{tabular}{ccccc}
\hline Grupo & Ordenação & \multicolumn{3}{c}{ Ordenação clone x delineamento } \\
\cline { 2 - 5 } & & STP & Retangular & Linha \\
\hline 1 & 1 & $14^{*}$ & 14 & 8 \\
& 2 & $4^{*}$ & 5 & 5 \\
& 3 & $13^{*}$ & 8 & 4 \\
& 4 & $8^{*}$ & 13 & 13 \\
& 5 & $5^{*}$ & 11 & 10 \\
& 6 & 6 & 4 & 14 \\
\hline 2 & 7 & 11 & 18 & 6 \\
& 8 & 10 & 16 & 16 \\
& 9 & $16^{*}$ & 12 & 11 \\
& 10 & $12^{*}$ & 2 & 17 \\
& 11 & 15 & 10 & 12 \\
& 12 & 9 & 1 & 15 \\
\hline 3 & 13 & $7 *$ & 6 & 3 \\
& 14 & 1 & 9 & 18 \\
& 15 & $3 *$ & 15 & 1 \\
& 16 & 02 & 17 & 9 \\
& 17 & $17 *$ & 3 & 2 \\
\hline
\end{tabular}

*clones que se repetem dentro do grupo nos três delineamentos
No grupo 1 (ordenamento de 1 a 6), cinco dos seis clones foram comuns nos três delineamentos, demonstrando alta concordância entre os delineamentos dos clones de bom desempenho.

No grupo 2, relativo aos clones com comportamento intermediário, houve grande dispersão, e apenas dois clones se repetiram nos três delineamentos.

Com relação ao grupo 3 (clones inferiores), dois clones se repetiram em todos os delineamentos. Nesse grupo, pelo menos três clones estavam presentes em pelo menos dois delineamentos distintos.

Os três delineamentos apresentaram ordenamentos similares nos clones de maior incremento volumétrico médio anual (IMA). Já nos clones com incremento inferior, a dispersão foi menor, comparativamente aos clones de comportamento intermediário.

Em relação às médias gerais ou predições (Tabelas 1, 2 e 3), os valores no delineamento STP (Tabela 3) foram levemente superiores. Levando-se em consideração que os materiais estavam implantados nas mesmas condições ambientais (solo, clima) e foram conduzidos sob as mesmas condições de manejo (adubação, espaçamento), isso, em princípio, não era esperado. Tal comportamento pode eventualmente ser casual, mas suspeita-se de que o delineamento possa permitir melhor exploração do espaço físico, por parte dos clones, pois cada um tem arquitetura diferente, tanto da parte aérea quanto radicular. Essa hipótese ainda precisa ser mais bem investigada.

De modo geral, o índice de acerto dos melhores materiais utilizando o delineamento STP demonstrou ser alto na seleção dos bons materiais (ordenamentos de 1 a 6). Isso indica que o STP, mesmo com maiores variâncias entre clones, possivelmente por alocompetição, pode ser viável para seleção de genótipos superiores, como visto a seguir.

\section{Análise conjunta entre os delineamentos experimentais}

Para essa avaliação foi realizada análise conjunta englobando os três delineamentos, usando-se o modelo misto com clone aleatório (REML/BLUP) e comparando as produtividades nos três delineamentos (Tabela 5).

A ordenação dos clones está separada em três grupos, sendo apresentada a concordância da análise conjunta com as análises individuais por delineamento. 
Tabela 5 - Comparação do ordenamento entre os clones na análise conjunta $\mathrm{x}$ análise individual por delineamento Table 5 - Ranking comparison between clones in joint analysis vs. individual analysis by design

\begin{tabular}{|c|c|c|c|c|c|c|}
\hline \multirow[t]{2}{*}{$\begin{array}{l}\text { Grupo na } \\
\text { análise conjunta }\end{array}$} & \multirow[t]{2}{*}{$\begin{array}{l}\text { Ordenação/ análise } \\
\text { conjunta }\end{array}$} & \multirow[t]{2}{*}{$\begin{array}{l}\text { Clone análise } \\
\text { conjunta }\end{array}$} & \multirow[t]{2}{*}{$\begin{array}{l}\text { IMA analise } \\
\text { conjunta }\end{array}$} & \multicolumn{3}{|c|}{$\begin{array}{l}\mathrm{N}^{\circ} \text { de clones presentes /grupo } \\
\text { em relação análise individual }\end{array}$} \\
\hline & & & & Retangular & Linear & $\mathrm{STP}^{1}$ \\
\hline \multirow[t]{6}{*}{01} & 1 & 14 & 49,88 & 5 & 5 & 6 \\
\hline & 2 & 8 & 47,25 & & & \\
\hline & 3 & 5 & 46,65 & & & \\
\hline & 4 & 13 & 46,60 & & & \\
\hline & 5 & 4 & 46,49 & & & \\
\hline & 6 & 6 & 43,16 & & & \\
\hline \multirow[t]{6}{*}{02} & 7 & 10 & 42,95 & 3 & 3 & 4 \\
\hline & 8 & 11 & 42,81 & & & \\
\hline & 9 & 16 & 42,08 & & & \\
\hline & 10 & 3 & 42,03 & & & \\
\hline & 11 & 15 & 39,54 & & & \\
\hline & 12 & 1 & 39,00 & & & \\
\hline \multirow[t]{6}{*}{03} & 13 & 9 & 38,01 & 3 & 4 & 4 \\
\hline & 14 & 17 & 37,18 & & & \\
\hline & 15 & 12 & 36,80 & & & \\
\hline & 16 & 7 & 36,78 & & & \\
\hline & 17 & 18 & 36,70 & & & \\
\hline & 18 & 2 & 34,70 & & & \\
\hline
\end{tabular}

${ }^{1}$ Single tree plot (parcela de planta única)

No grupo 1, os seis clones de melhor desempenho só se repetiram em sua totalidade na análise individual do delineamento STP. Já nos demais delineamentos cinco, entre os seis melhores clones, se repetiram nas análises conjuntas e individuais.

Com relação aos clones dos grupos 2 e 3 , eles não se repetiram na totalidade das análises conjuntas e individuais. No entanto, em ambos os grupos o delineamento STP apresentou o maior número de clones coincidentes entre a análise conjunta e a individual.

\section{CONCLUSÕES}

\section{Modelos de Análise de Variância}

Os três modelos de análise (tradicional, misto com clone fixo e misto com clone aleatório) não alteraram os ordenamentos dos clones nos delineamentos de parcelas lineares e de uma única planta. No modelo misto com clone aleatório (REML/BLUP), no delineamento de parcelas retangulares houve alteração de posição entre os clones de desempenho intermediário.

A principal diferença entre os modelos de análise está na amplitude de variação entre os clones de melhor e pior desempenho, em que as análises pelo REML/ BLUP reduzem as predições das médias, o que pode ser atribuído ao fato de essas diferenças estarem mais livres de efeitos ambientais.

\section{Parcelas Experimentais}

Os experimentos envolvendo as três formas de parcelas resultaram em ordenamentos similares dos clones de maior incremento volumétrico médio anual (IMA). Nos clones de desempenho intermediário, existe maior dispersão no ordenamento. Nos clones com desempenho inferior, a dispersão é menor. Por ser de custo menor, mesmo com maior variância entre clones, o delineamento de parcela única (STP) pode ser recomendado para seleção de genótipos com alto índice de acerto, não havendo, portanto, a necessidade de uso de parcelas maiores.

As parcelas maiores, ou plantios-piloto, são indicadas e até necessárias quando se deseja melhor precisão do valor do IMA em escala operacional.

\section{REFERÊNCIAS}

ANDRADE, H. B. et al. Alternativas para atenuar a diferença de estande nos experimentos de avaliação de clones de Eucalyptus urophylla. Revista Árvore, v.30, n.1, p.11-18, 2006.

DUARTE, J. B.; VENCOVSKY, R. Estimação e predição por modelo linear misto com ênfase na ordenação de médias de tratamentos genéticos. Scientia Agrícola, v.58, n.1, p.109-117, 2001. 
GARCIA, C. H. Tabelas para classificação do coeficiente de variação. Circular Técnica IPEF, n.171, p.1-11, 1987.

GOMES, F. P.; COUTO, H. T. Z. O Tamanho ótimo de parcelas experimentais para ensaios com Eucaliptos. Circular Técnica do IPEF, n.31, p.75-77, 1985.

HENDERSON, C. R. The best linear unbiased estimation and prediction under a selection model. Biometrics, v.31, p.423-449, 1975.

HIGASHI, E. N.; SILVEIRA, R. L.; NATAL, A. G. Propagação vegetativa de Eucalyptus: princípios básicos e sua evolução no Brasil. Circular Técnica do IPEF, n.192, p.1-11, 2000

HOULE, D. Comparing evolvability and variability of quantitative traits. Genetics, n.30, p.195-204, 1992.

RAMOS, A. A.; VALENCIA, E. F. T.; WECHSLER, F. S. Heterogeneidade da variância das características produtivas de bovinos da raça Holandesa nos trópicos. I-Estratificação por nível de produção do rebanho. In: REUNIÃO ANUAL DA SOCIEDADE BRASILEIRA DE ZOOTECNIA, 33., 1996, Fortaleza. Anais... Fortaleza: 1996. p.71-73.

RESENDE, M. D. V. Delineamentos de experimentos de seleção para a maximização da acurácia seletiva e do progresso genético.

Revista Árvore, v.19, n.4, p.479-500, 1995.
RESENDE, M. D. V. Estimação de componentes de variância e predição de valores genéticos pelo método da máxima verossimilhança restrita (REML) e melhor predição não viciada (BLUP) em Pinus. Boletim de Pesquisa Florestal, n.32/33, p.23-42, 1996.

RESENDE, M. D. V. Análise estatística de modelos mistos via REML/BLUP na experimentação em melhoramento de plantas perenes. Colombo: Embrapa Florestas, 2000. 101p. (Embrapa Florestas. Documentos, 47).

SAS. Institute Inc. SAS Procedures Guide. Version 8 (TSMO). Cary: 1999. 454p.

SILVA, R. L. et al. Determinação do tamanho ótimo da parcela experimental pelos métodos da máxima curvatura modificado, do coeficiente de correlação intraclasse e da análise visual em testes clonais com Eucalipto. Revista Árvore, v.27, n.5, p.669-676, 2003.

VENCOVSKY, R.; BARRIGA, P. Genética biométrica no fitomelhoramento. Ribeirão Preto: Sociedade Brasileira de Genética, 1992. p.93-109.

ZANON, M. L. B.; STORCK, L. Tamanho de parcelas experimentais para Eucalyptus saligna Smith. Ciência Rural, v.27, n.4, p.581-593, 1997.

ZOBEL, B. J. Clonal forestry in the eucalypts. In: AHUJA, M. R.; LIBBY, W. J. (Eds). Clonal forestry: conservation and application. Berlin: Springer-Verlag, 1993. p.139-148. 